\title{
Redefinición de roles y relaciones de género en las migraciones internacionales. Estudio cualitativo en el Estado de Tamaulipas
}

\author{
Rocío Cárdenas-Rodríguez \\ Teresa Terrón-Caro \\ $\mathrm{M}^{\mathrm{a}}$ Carmen Monreal-Gimeno
}

\author{
Universidad Pablo de Olavide, España
}

Resumen

El aumento de mujeres que inician la cadena migratoria, ha producido un cambio cualitativo en el proceso. Múltiples investigaciones, incluida la nuestra, han puesto de manifiesto cómo la mujer adopta un rol activo, tanto en la toma de decisiones e iniciativas, como en la consecución de sus objetivos. Esto confiere a las migrantes una mayor independencia y las convierte en forjadoras de su propio destino y del de sus hijos/as. Mantienen las vinculaciones familiares, pero están expuestas a mayores riesgos. Su dependencia les ha desvalorizado frente a sí mismas y la sociedad, pudiendo ser abusadas y golpeadas, sin que ello se considere una violación de sus derechos. Culturalmente, se han distribuido los roles sociales (productivo/ reproductivo), en función de la atribución de características opuestas a hombres y mujeres, generando desigualdades.

Palabras clave: Género, Migración Femenina, Socialización, Roles.

\section{Abstract}

Redefinition of gender roles and relations in international migrations. Qualitative study in the State of Tamaulipas

The increase in women initiating migration chain, has been a qualitative change in the process. Multiple investigations, including ours, have shown how the woman takes an active role in both decision making and initiatives, and in the pursuit of its objectives. This gives the migrants a greater independence and makes them become shapers of their own destiny and that of their sons / daughters. They maintain family ties but are exposed to greater risks. Their dependence has been devalued against themselves and society, they can be abused and beaten, but it is considered a violation of their rights. Culturally, social roles (productive / reproductive) were distributed, depending on the attribution of characteristics opposite to men and women, creating inequality.

Key words: Gender, stereotypes, female migration, education. 


\section{INTRODUCCIÓN}

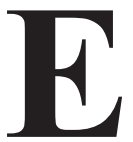

$\mathrm{s}$ un hecho reconocido que el fenómeno migratorio cambia constantemente debido a "coordenadas sociales, políticas y económicas de cada momento" (Martín, Martínez y Martínez, 2014: 4). Uno de las transformaciones más significativos, desde nuestro punto de vista, ha sido el aumento de la visibilidad que, aunque aún en proceso, se produce de los movimientos poblacionales femeninos con todo lo que ello supone (García-Moreno, 2015). Abordar este fenómeno teniendo presente la perspectiva de género pone de manifiesto que los procesos migratorios femeninos "tienen una identidad propia, con causas y consecuencias diferentes, al jugar la mujer un rol económico y social diferente al del hombre, tanto en la esfera productiva como en la reproductiva, y a la vez en la sociedad de origen y en la de destino" (Ciurlo, 2015: 57).

La creciente presencia de la mujer en los movimientos poblacionales no sólo tiene que ver con las estadísticas migratorias sino con el papel cada vez más decisivo que desempeñan las mujeres en el ciclo migratorio. Es cada vez mayor el número de mujeres que inician la cadena migratoria, cambian las características de la misma, ellas se convierten en protagonistas del proceso y no en seguidoras del proyecto migratorio del marido u otros hombres de la familia. Situación que les otorga mayor autonomía. En la literatura sobre las migraciones con enfoque de género, se pone de manifiesto como la mujer, cada vez en mayor medida, es "el primer eslabón de las redes sociales que van a desarrollar la dinámica migratoria..." (Micolta, 2007: 15), indispensable en el proceso de migraciones internacionales. Además, la mujer también es reconocida como factor esencial en el asentamiento e integración de la población inmigrante en las sociedades de llegada, especialmente de algunas comunidades. En definitiva, siguen manteniendo en mayor medida las vinculaciones familiares, y a su vez están expuestas a mayores riesgos dada las desigualdades de género tanto en los países de origen como de destino.

Por otro lado, las desigualdades de género hacen que las causas y las consecuencias de la experiencia migratoria sean muy diferentes para hombres y mujeres, desigualdades que permiten que las mujeres migrantes sigan invisibilizadas. En este sentido, según Godoy (2007) las desigualdades de género y los estereotipos de género permiten explicar la decisión de migrar, las redes empleadas para hacerlo, la inserción social y laboral en el país de acogida, así como los significados que las personas atribuyan a esta experiencia. A su vez, las migraciones influyen en las relaciones de 
género, ya sea afianzando las desigualdades y roles tradicionales, o bien desafiándolos. La migración supone una redefinición de los roles de género, aunque estos cambios no conllevan necesariamente una disminución de las desigualdades (León, 2014).

Podemos afirmar que, aunque para algunas mujeres la migración puede tener una connotación positiva (mejoras económicas, oportunidades laborales y educativas...) y para otras mujeres connotaciones más negativa (castigo, desarraigo, desintegración...), según Godoy (2007) en la experiencia de la mayoría de las mujeres la migración parece reforzar y al mismo tiempo desafiar roles y estereotipos de género.

En este sentido, la incorporación de la mujer al mercado laboral podemos entenderla como una consecuencia positiva, pues, normalmente, le posibilita redefinir los roles desiguales asociados al género, que las conduce en muchas ocasiones a un mayor desarrollo personal y social y por tanto les permite desarrollar nuevas estrategias de supervivencia. Pero a su vez, una consecuencia negativa para ellas es que la migración constituye un largo proceso en el que las mujeres antes de llegar al lugar de destino van afrontando situaciones que no se les plantean a sus compañeros de migración porque son resultado de una desigualdad específica, las sufren por el hecho de ser mujeres, es decir que se produce porque existe una relación jerárquica entre hombres y mujeres, desigualdad que se suma a otras desigualdades como pueden ser la pobreza, el color de la piel etc.

Consideramos importante comprender el papel que cumplen las mujeres migrantes en el ciclo migratorio desde una mirada en la que se analicen las dimensiones de género, experiencias vitales y culturales de ser mujer o de ser hombre y, por otra, de cumplir roles de pareja o de esposos o esposas.

En el presente artículo se abordará el análisis del papel de la mujer en el hecho migratorio desde los ámbitos conceptuales de rol de género y de socialización de género, con el fin de comprender mejor los procesos y mecanismos de asignación de roles (femeninos o masculinos) desde las prácticas que la sociedad determina.

\section{Metodología del estudio}

Para tener un conocimiento más exhaustivo de cómo las relaciones desiguales de género inciden en el proceso migratorio desarrollamos un estudio cualitativo basado en los resultados del proyecto titulado "Mujeres migrantes indocumentadas: historias de transgresión, resistencia, sumisión y reacomodo como estrategias de viaje. Una perspectiva socioeducativa" 
financiado por el Plan Propio de Cooperación de la Universidad Pablo de Olavide. ${ }^{1}$ La investigación se realizó durante 2011 en el estado norteño de Tamaulipas, México, en tres ciudades fronterizas (Matamoros, Reynosa y Nuevo Laredo). Tales ciudades son los puntos finales de un corredor terrestre ampliamente frecuentado por migrantes centroamericanos y mexicanos. Para ello se llevaron a cabo 26 entrevistas en profundidad a mujeres migrantes indocumentadas localizadas en los albergues de Tamaulipas (Tabla 1); así como 12 entrevistas abiertas a informadores claves-profesionales de distintas dependencias gubernamentales y miembros de la sociedad civil organizada.

Las preguntas que hicimos en este estudio fueron:

- ¿Cómo se manifiestan los estereotipos de género en el proceso migratorio?

- ¿Cómo afecta el proceso migratorio femenino al contexto familiar?

- ¿Qué peligros sufren las mujeres migrantes por ser mujer y qué recursos utilizan para minimizarlas?

En consecuencia, los objetivos del presente artículo son:

1. Establecer cómo afectan los estereotipos de género a las mujeres migrantes.

2. Analizar si el proceso migratorio propicia un cambio de roles en el ámbito familiar y comunitario.

3. Analizar los peligros a los que se exponen las mujeres migrantes durante el trayecto y qué recursos utilizan para intentar minimizar los riesgos.

Para dar respuesta a las preguntas de investigación plantearemos en primer lugar elementos teóricos sobre los estereotipos de género, los esquemas de género, y cómo se aprenden estos estereotipos, contextualizando parte de esta teoría en el contexto migratorio.

\footnotetext{
${ }^{1}$ Investigación: Mujeres migrantes indocumentadas: Historias de transgresión, resistencia, sumisión y reacomodo como estrategias de viaje. Una perspectiva socioeducativa. Financiado por el Plan Propio de Cooperación Internacional al Desarrollo de la Universidad Pablo de Olavide, Sevilla, España (Resolución de 10 de febrero de 2011).
} 
Redefinición de roles y relaciones de género en las migraciones internacionales. Estudio ... / R. CÁRDENAS et al.

Tabla 1: Resumen de entrevistas a mujeres migrantes

\begin{tabular}{|c|c|c|c|c|c|}
\hline $\begin{array}{l}\text { Edad } \\
\text { (años) }\end{array}$ & $\begin{array}{c}\text { Lugar de } \\
\text { residencia habitual }\end{array}$ & Estado Civil & $\mathrm{N}^{0}$ de hijos & Nivel educativo & Viaja sola o acompañada \\
\hline 30 & Veracruz & Casada & 3 & Primaria & Acompañada de esposo \\
\hline 18 & $\begin{array}{c}\text { Nuevo Laredo, } \\
\text { Tamaulipas, México }\end{array}$ & Casada & Embarazada & Secundaria & Acompañada de esposo \\
\hline 25 & Zapata, Texas & Casada & 4 & Primaria & Sola \\
\hline 42 & $\begin{array}{l}\text { Tuxpan, Veracruz, } \\
\text { México }\end{array}$ & $\begin{array}{c}\text { Casada por } 15 \\
\text { años }\end{array}$ & 3 & $\begin{array}{l}\text { Sin estudios } \\
\text { (no concluyó } \\
\text { primaria) }\end{array}$ & Sola \\
\hline 45 & Veracruz & Unión Libre & 4 & $\begin{array}{c}\text { Sin estudios } \\
\text { (no concluyó } \\
\text { primaria) }\end{array}$ & Acompañada de pareja \\
\hline 37 & $\begin{array}{c}\text { Izúcar de } \\
\text { Matamoros, Puebla }\end{array}$ & $\begin{array}{c}\text { Unida (pareja } \\
\text { en Estados } \\
\text { Unidos) }\end{array}$ & 4 & Primaria & Acompañada de ahijada \\
\hline 37 & $\begin{array}{l}\text { Vivió } 20 \text { años en } \\
\text { Estados Unidos }\end{array}$ & Unión Libre & 0 & Primaria & Sola \\
\hline 25 & Torreón, Coahuila & Unión Libre & 1 & Secundaria & Sola \\
\hline 33 & Honduras & Unión Libre & 4 & Sin estudios & $\begin{array}{c}\text { Acompañada de conocidos } \\
\text { y pareja }\end{array}$ \\
\hline 25 & Cuenca, Ecuador & Unión Libre & 1 & $\begin{array}{c}\text { Secundaria }\left(2^{\circ} \text { año }\right. \\
\text { de Universidad })\end{array}$ & Acompañada de primos \\
\hline 31 & Honduras & Unión Libre & 4 & $\begin{array}{c}\text { Sin estudios } \\
\text { (no concluyó } \\
\text { primaria) }\end{array}$ & $\begin{array}{c}\text { Sola, encontró pareja en el } \\
\text { viaje }\end{array}$ \\
\hline 25 & Honduras & Unión Libre & 1 & $\begin{array}{l}\text { Graduada en } \\
\text { Secretariado }\end{array}$ & Acompañada \\
\hline 50 & San Antonio, Texas & Soltera & 2 & $\begin{array}{c}\text { Sin estudios (no } \\
\text { concluyó primaria) }\end{array}$ & Sola \\
\hline 46 & Chicago, Illinois & Soltera & 4 & $\begin{array}{l}\text { Sin estudios (no } \\
\text { concluyó primaria) }\end{array}$ & Sola \\
\hline 20 & $\begin{array}{c}\text { Izúcar de } \\
\text { Matamoros, Puebla }\end{array}$ & Soltera & 1 & Secundaria & Acompañada \\
\hline 29 & $\begin{array}{l}\text { San Pedro Mártir, } \\
\text { Oaxaca, México }\end{array}$ & Soltera & 1 & Primaria & $\begin{array}{c}\text { Acompañada de hija de } 4 \\
\text { años }\end{array}$ \\
\hline 37 & El Salvador & Soltera & 4 & Secundaria & $\begin{array}{c}\text { Acompañada de hija de } 12 \\
\text { años }\end{array}$ \\
\hline 22 & Guatemala & Soltera & 1 & Universitario & Acompañada de hermano \\
\hline 52 & El Salvador & Soltera & 2 & Sin estudios & Sola \\
\hline 23 & Ciudad de México & Soltera & 0 & Sin estudios & Acompañada de padre \\
\hline 33 & $\begin{array}{c}\text { Acapulco, Guerrero, } \\
\text { México } \\
\end{array}$ & Soltera & 0 & Primaria & Acompañada \\
\hline 21 & Puebla & $\begin{array}{l}\text { Soltera sin } \\
\quad \text { hijos }\end{array}$ & 0 & $\begin{array}{l}\text { Secundaria (dos } \\
\text { años de } \\
\text { universidad) }\end{array}$ & $\begin{array}{l}\text { Sola, en el viaje iba un } \\
\text { conocido de su pueblo }\end{array}$ \\
\hline 21 & Oaxaca & Soltera & 0 & Preparatoria & Acompañada \\
\hline 23 & Oaxaca & Soltera & 0 & $\begin{array}{c}\text { Sin estudios (no } \\
\text { concluyó primaria) }\end{array}$ & Sola \\
\hline 20 & $\begin{array}{l}\text { Rayón, S.L.P. } \\
\text { México }\end{array}$ & Soltera & 0 & Secundaria & Sola \\
\hline 21 & Honduras & Soltera & 0 & Bachillerado & Acompañada \\
\hline
\end{tabular}

Para más información sobre el perfil de las mujeres migrantes protagonistas del estudio, consultar Terrón y Monreal (2014).

Fuente: elaboración propia a partir de la información recogida en el trabajo de campo de la investigación. 
En un segundo lugar, analizaremos las entrevistas realizadas en relación a cómo influyen estos estereotipos en las migraciones femeninas y qué repercusiones tiene la socialización diferenciada en las mujeres migrantes, y para ello centraremos el discurso en tres variables: i) cómo se presentan los estereotipos de género en las mujeres migrantes en lo relativo al ámbito productivo; ii) consecuencias del proceso migratorio de las mujeres en el ámbito familiar; iii) los peligros y riesgos a los que se enfrentan las mujeres en su proceso migratorio y qué recursos utilizan.

\section{MigRaCiONES Y SOCIALIZACIÓN DIFERENCIAL DE IDENTIDADES DE GÉNERO}

Para comprender mejor la interrelación entre género y procesos migratorios, nos detendremos a analizar aspectos tan importantes como la socialización o los estereotipos de género que como ya hemos indicado marcan las relaciones entre los hombres y las mujeres en las diversas culturas.

En todas las sociedades el sexo es una de las características más significativas con la que nos presentamos en las relaciones con otras personas y un potente descriptor alrededor del cual organizamos nuestra identidad. Sin profundizar en los debates surgidos con respecto a la influencia biológica y/o cultural en las relaciones de género, queremos precisar que el sexo hace referencia a las características físicas, que definen a las personas como hombres y mujeres, mientras que el género se refiere a las conductas asociadas a los roles.

Concebir el género como una construcción social implica entenderlo como el resultado de un conjunto de prácticas, actividades y experiencias organizadas en torno a un sistema social determinado, que presenta ideales distintos para hombres y mujeres. A su vez, esta perspectiva nos permite conocer y estudiar las diferencias en la construcción del género que se establecen desde diferentes culturas. Además, la consideración de que el individuo no es un mero receptor pasivo de esas normas o expectativas sociales nos lleva a pensar que la persona interviene de forma activa en el desarrollo de su propio género.

El género se construye a través de la interacción con los demás y dentro de diversos contextos socioculturales, que originan unas expectativas diferentes para cada uno de los sexos, y bajo estas diferentes identidades se establecen diferencias psicológicas y sociales entre hombres y mujeres, que justifican la diversidad de roles, que influirán en sus relaciones y también en la forma en que se ven a sí mismos. 
Por otro lado, en las sociedades donde se ha producido una transformación de los roles tradicionales (masculino/femenino) nos encontramos en un proceso de (re)construcción de las identidades masculinas y femeninas $\mathrm{y}$, derivado de ello, de los roles de género desempeñados por uno u otro sexo. Podríamos afirmar que estas diferencias entre géneros ya no parecen ser tan claras y, en consecuencia, la relación jerárquica de hombres y mujeres, puede que haya comenzado a desdibujarse. Esta transformación no se produce del mismo modo y al mismo ritmo en todas las zonas, países o comunidades; mientras que en las más desarrollados económicamente se van transformado las relaciones ente hombres y mujeres en los ámbitos público y privados, en otras se mantienen las formas más tradicionales de relación. Hemos de tener en cuenta estas diferencias de culturas y creencias cuando analizamos la situación de las mujeres en la sociedad de origen y en la sociedad de llegada, así como en el proceso migratorio.

Así, aunque no podemos negar la posible influencia de la naturaleza sobre nuestros comportamientos, queremos hacer hincapié en este apartado en el papel que desempeñan la cultura, la educación y las interacciones sociales en la construcción del género.

Ser hombre o mujer implica haber interiorizado una realidad (creencias, valores, comportamientos dominantes) que ya está dada en el entorno cultural, lo que nos conduce a desarrollar una serie de actitudes frente a lo exigido, como comportamientos, sentimientos y pensamientos propiamente femeninos o masculinos, proceso de aprendizaje que se le conoce como socialización de género (Monreal-Gimeno y Martínez-Ferrer, 2010). La concepción diferente de hombres y mujeres frente a la vida responde a unas creencias fundamentadas en el estereotipo construido culturalmente y transmitido a las nuevas generaciones. Según estas creencias interiorizadas por cada uno de nosotros/as el hombre debe de ser fuerte, agresivo, emprendedor, mientras que la mujer debe de ser sumisa, débil, características que a su vez responden a las percepciones sobre la complexión física de unos y otras.

La socialización humana comprende, de hecho, todas las influencias (negativas y positivas) provenientes de las múltiples instancias sociales (familia, comunidad de convivencia, instituciones educativas y religiosas, políticas, económicas, culturales y las representaciones sociales) que actúan en la vida de las personas, conformando su experiencia social. La socialización abarca, por tanto, todos los procesos mediante los cuales el ser humano biológico deviene en un ser social. Una de las primeras expe- 
riencias socializadoras, y posiblemente la que más define a la persona, es la del género.

En el caso concreto de estudio, la socialización diferencial de género tiene como consecuencia que las mujeres migrantes presenten identidades diferenciadas respecto a los hombres migrantes a la hora de percibir hechos, riesgos, oportunidades..., y a la forma de enfrentarse a esos riesgos durante el proceso migratorio.

Distintos estudios han puesto de manifiesto que las mujeres migrantes están expuestas a más riesgos que los hombres en cuanto a discriminación, explotación y violencia, durante la travesía o en los lugares de destino. Como nos indica Martínez Pizarro (2003) la confluencia de género, etnia, nacionalidad e indocumentación puede conducir a la más extrema de las violaciones de los derechos humanos y a la máxima vulnerabilidad. En la misma línea nos indica Monzón (2006), la trata o el "tráfico" de las mujeres migrantes supone que es mejor para las mujeres quedarse en su casa que iniciar el viaje y meterse en problemas que dañarán profundamente a las mujeres, mientras que se espera que los hombres se enfrenten y superen los problemas de manera rutinaria.

La perspectiva de género más tradicional concibe a las mujeres migrantes como víctimas inocentes arrancadas de sus casas, coaccionadas y obligadas a emigrar y hasta secuestradas o vendidas como esclavas; sin embargo, Agustín (2003) nos indica otra perspectiva de género que rechaza la victimización y plantea que las mujeres migrantes, incluso la más pobre o que haya sido "vendida" o secuestrada, buscan y encuentran lugares para desarrollarse: escapan, buscan trabajo, establecen redes de apoyo..., hacen lo mismo que los migrantes hombres: aprender a adaptarse a las circunstancias.

En cualquier caso, la feminización de las migraciones y el estudio del género dentro de los movimientos migratorios ponen en evidencia la importancia que puede tener el género en la constitución de los fenómenos migratorios. En este sentido, Godoy (2007) afirma que la experiencia migratoria influye en la visión que las mujeres tienen de sí misma, en la identidad de estas mujeres.

Desde nuestro posicionamiento, consideramos importante realizar el análisis de los procesos migratorios desde una perspectiva de género desde el origen, y no sólo analizar las experiencias, expectativas y las consecuencias en el país de llegada.

Otro elemento que puede modificar la identidad de género de las mujeres durante su experiencia migratoria es el empleo, el hecho de que las 
mujeres migrantes a través del empleo puedan alcanzar una independencia económica. El poder adquisitivo que alcanzan algunas mujeres inmigrantes puede generar cambios de roles en la estructura familiar siendo las principales proveedoras de las familias. Sin embargo, según (Carretero Palacios, 2015), estos efectos pueden quedar minimizados por las restricciones que tienen las mujeres migrantes en el acceso al trabajo, ocupando los puestos laborales más bajos de la escala social. En esta misma línea, Klein y Vázquez-Flores (2013) sostiene que los procesos migratorios incrementan las desigualdades de género en cuanto a salarios bajos, trabajos insalubres, agresión y acoso sexual. Sin embargo, otros autores como Canales y Zlolniski (2001) sostienen que las mujeres migrantes entran en contacto con otras realidades culturales con códigos de géneros distintos, que chocan con algunos roles y códigos de género tradicionales.

A continuación presentamos los resultados obtenidos en el estudio que plantea cómo la identidad de género de las mujeres migrantes influye en el ámbito productivo, familiar y en la constitución de redes de apoyo y cómo, a su vez, esas identidades se redefinen.

\section{LAS MUJERES MIGRANTES EN TRÁNSITO: REPERCUSIONES EN EL ÁMBITO PRODUCTIVO, EN LA FAMILIA Y EN LAS REDES DE APOYO}

Tal y como hemos planteado al inicio del artículo, vamos a presentar el análisis de las entrevistas realizadas intentando dar respuesta a las preguntas de investigación planteadas en la introducción.

\section{Las mujeres migrantes y las repercusiones del proceso migratorio en el ámbito productivo}

Como ya hemos indicado la migración de las mujeres puede desafiar los roles de género tradicionales ya que posibilitan la inclusión de las mujeres en la esfera pública, el trasvase de poder en las relaciones desiguales de género e implicar procesos de desarrollo personal en las mujeres y en algunos hombres y así promover el cambio social. El acceso de las mujeres que migran al mercado laboral está contribuyendo de forma decisiva a mejorar la situación económica femenina tanto en los países de acogida como en sus países de origen. Ellas a la vez que adquieren independencia económica, van conociendo nuevas ideas, imaginarios, símbolos, creencias y estructuras, que les proporciona más confianza en sí mismas y libertad a través de la migración. Es lo que se ha definido como "remesas sociales" (Levitt, 1996) y que pueden tener un impacto profundo en el desarrollo y el fomento de la igualdad, incluida la igualdad de género. Las mujeres migrantes 
envían dinero a sus hogares adquiriendo nuevos roles y transmitiendo nuevas imágenes, la aportación económica fruto de su trabajo desmiente la idea de que la mujer debe dedicarse exclusivamente al trabajo reproductivo y a su vez la revaloriza lo que tiene efecto tanto en sus familias como en sus comunidades.

En varias de las entrevistas realizadas se manifiesta cómo las mujeres migrantes envían parte del dinero que obtienen trabajando a sus hogares de origen para mantener a sus hijos e hijas o a otros familiares. Presentamos como ejemplo el testimonio de una mujer migrante de Veracruz.

Entrevistadora: Si dejó a sus hijos allá en Veracruz ¿con quién se quedaron a vivir?

Entrevistada: Allá se quedaron con su abuelo.

Entrevistadora: ¿Y cómo se mantenían sus hijos?

Entrevistada: Pues mi suegro hace pan y nosotros lo que le podíamos mandar del otro lado, le mandábamos dinero (Mujer de 42 años de Veracruz, México). Todo el ingreso que yo tenía era para depositarlo a mis hijos porque como ellos están aquí (en México) y yo cobraba mi cheque y lo cambiaba y lo enviaba a mis hijos, y luego tenia que dejar para comida, para mi renta (Mujer de 46 años de Puebla, México).

Por otro lado, tal y como hemos indicado, la actividad productiva de las mujeres migrantes tiene una repercusión positiva en la comunidad de origen, tanto en el dinero que la familia recibe como en la percepción que se tiene de esas mujeres. En algunos casos, las mujeres migrantes que regresan a su comunidad y que han tenido éxito en su proceso migratorio sirve de modelo para otras mujeres, se convierten en un ideal basado en las cosas que han conseguido en Estados Unidos a través del trabajo sin contemplar los riesgos que conlleva todo el proceso.

Entrevistada: Yo he visto que cuando las mujeres se van y regresan, pues llegan con camioneta y con cosas, y con dinero para la familia. (...) yo tengo una prima que se fue sola para allá, se puso a trabajar en un restaurante y le fue muy bien (NL42-Veracruz).

En ese sentido, el hecho de que las mujeres migrantes pasen a ser proveedora hace que mejore su estatus y aumente su poder de negociación en el núcleo familiar. Este nuevo rol altera las relaciones de género a nivel económico y también simbólico, y el acceso a la esfera productiva otorga ciertos privilegios sociales que el rol reproductivo no conlleva (Ramírez, García y Míguez, 2005). 
De esta forma, la migración posibilita a las mujeres el acceso al mercado laboral, sobre todo cuando viene de un contexto donde los estereotipos de género le han conferido a estas mujeres un espacio privado y reproductivo. Así se expresaba una de las mujeres entrevistadas: “...si Dios quiere vas a llegar, allá tú vas a llegar a trabajar. Acá tú no trabajas, tú sólo te encargas de limpiar, hacer la comida, y cuando no tienes que hacer te acuestas. Allá en Estados Unidos tienes que trabajar" (M23-Oaxaca).

En relación a las mujeres que deciden iniciar el proyecto migratorio muchas de ellas que forman parte de actividades productivas asumen la jefatura del hogar y amplían su participación social en los espacios públicos. Es decir, se adentran en espacios sociales proscritos por la división sexual del trabajo con anterioridad a la migración. Las mujeres que migran comienzan a transitar por nuevos espacios, a acudir solas a las compras o a desplazarse por la ciudad, participar en actos sociales, administrar el dinero y participar más activamente en asambleas religiosas (Dáubeterre, 2005). Sin embargo, no podemos olvidar que este hecho no implica el abandono de los trabajos reproductivos. Bien directamente, bien por medio de redes femeninas de apoyo o empleo de otras mujeres, las mujeres migrantes deben tratar de conciliar la vida laboral, familiar y personal en destino y en origen.

Sin embargo, a pesar de que la migración femenina puede fomentar un cambio en las relaciones desiguales de género, también puede afianzar los roles de género tradicionales ya que los procesos de renegociación de los relaciones y roles de género albergan una gran diversidad de realidades y posibilidades. Por un lado, la fuerte segmentación de género de los mercados de trabajo de los países receptores implica una doble discriminación sobre las migrantes. Se insertan en sectores precarios y mal remunerados y este hecho refuerza los roles tradicionales de género, puesto que trabajan en lo que las mujeres autóctonas no quieren, trabajos precarios, mal remunerados, invisibilizadas y aisladas de la esfera pública, en lo que se ha denominado transferencia de cuidados (Monreal, Povedano y Rodríguez, 2012).

En ese sentido, presentamos el testimonio de una mujer emigrante deportada de Estados Unidos presenta así sus años de trabajo allí: "Pues nada, que la vida está difícil, que si quieren te pagan y si no quieren te echan a los de inmigración o llaman a la policía" (NL25-Honduras).

Por otro lado, su participación en redes sociales de migrantes puede tener un efecto de control social, aumentando las desigualdades de género, ya que en muchas ocasiones estas asociaciones están atravesadas por 
las jerarquías de género importadas de las sociedades de origen. Pero en otras ocasiones la migración, pone de manifiesto la situación precaria de la mujer porque, las habilidades que las mujeres adquieren al incorporarse a la fuerza laboral les posibilitan asumir nuevos roles en sus hogares, convirtiéndose en muchas ocasiones en las principales proveedoras de ingresos y lo que podría constituir un motivo de empoderamiento y seguridad, puede dar lugar a que los hombres reaccionen a estos cambios con depresión, alcoholismo, aumento de abandonos de la familia o de violencia de género en público o en privado (Jolly, 2005). En muchas ocasiones, los hombres no aceptan los nuevos roles que las mujeres asumen como jefas del hogar y mucho menos los cambios que supondrían para ellos una redistribución de las tareas productivas y reproductivos de forma más equitativa para ambos géneros.

En Los Angeles empezó su machismo bien raro, sintió como que yo era su trofeo o algo así (...) sólo que cuando bebía se ponía más loco, nadie me podía voltear a ver, yo no podía hablar ni con mujeres, y yo trabajaba en dos trabajos y él no quería que yo lo hiciera, y yo no quería ya estar con él, mis sentimientos ya no eran los mismos (...) él me decía, el día que yo te vea con otra persona te mato a tí y a la otra persona, entonces no vas a ser feliz aquí (en Los Ángeles) con nadie, te voy a echar a la migración (NL25-Honduras).

\section{Las mujeres migrantes y las repercusiones en el ámbito familiar}

En los procesos migratorios de las mujeres migrantes las redes de solidaridad femenina se afianzan e incluso se amplían, ya que son otras mujeres las que pasan a ocuparse de las tareas reproductivas de las mujeres migrantes. Este hecho, tiene beneficios evidentes de aumento de redes solidarias, pero también hay que tener en cuenta la sobrecarga de trabajo de las mujeres que quedan en el hogar o la transferencia de las desigualdades de género si la familia decide emplear a otra mujer que podría ser a su vez migrante.

Estos cambios también afectan a las mujeres de hombres migrantes que permanecen en sus comunidades y adquieren nuevos roles, con más carga de trabajo, pero con mayor poder en la toma de decisiones económicas, familiares y comunitarias en representación de su marido ausente. Así, además de los beneficios económicos de la migración, las mujeres pueden tener acceso a nuevos espacios de participación social y a la renegociación de los roles de género, incrementando el poder en la toma de decisiones, la confianza en sí mismas y mayor autonomía. Sin embargo, hay autores como Palma (2004: 35) que en su estudio ponen de manifiesto un fenóme- 
no denominado "viudez blanca" entre las mujeres de hombres migrantes que permanecen en el hogar. La "viudez blanca" hace referencia a que "muchas veces la mujer queda prisionera del rol de esposa frente a sus hijos, la familia suya y del esposo y la comunidad, sin tener la posibilidad de vivir a plenitud ese rol por la ausencia del cónyuge. Esto se agrava por la necesidad de asumir aspectos de los roles de esposo y padre que ejercía el cónyuge ausente. En consecuencia, esa viudez blanca es una especie de cárcel invisible pero que sujeta a la mujer férreamente". Este rol tradicional de la mujer basado en la autoridad masculina tiende a reforzar el control que ejercen los parientes del marido sobre sus parejas en las comunidades de origen.

Un aspecto importante que presenta diferencias según el proceso migratorio lo inicien las mujeres o los hombres es la mayor vinculación de las mujeres a la familia, sean hijos/as que dejan en el lugar de origen o padres o madres. La mayoría de las mujeres entrevistadas tienen hijos menores que dejan en sus comunidades de origen a cargo de sus madres (principalmente) o hermanas, y en algún caso a cago de sus esposos.

Mi bebito de tres años se quedó con mi mamá (NL22-Guatemala).

Mis cuatro hijos se quedaron con mi hermana (NL31-Honduras).

Mi hijo de dos años se quedó con mi mamá (NL25-Coahuila).

Tengo tres hijos en México que están con mi mamá y una en New York (M46Puebla).

Tengo una hija de cuatro años y medio que está con mi mamá (NL25-Honduras).

Tengo tres hijos que se quedaron en Veracruz con su abuelo (NL42-Veracruz).

Hemos podido comprobar como las mujeres tienen presente la necesidad de traer a sus hijos e hijas con ellas para que tengan una vida mejor, puedan recibir educación, etc. Se concibe la educación como el medio para la promoción social, combatir las desigualdades, es importante para ellas para que sus hijos e hijas puedan conseguir estudios superiores a los de sus padres y madres, para avanzar en la escala social:

Y yo pues digo que, para ella, si pasa al otro lado, es un bienestar para ella porque está chiquita, puede aprender inglés y un, ya más grandecita, su trabajo (M37-El Salvador).

Entrevistadora: ¿Qué esperas obtener en Estados Unidos?

Entrevistada: Estar con los niños y que estudien allá. Y trabajar allá para darles a ellos una vida mejor (NL25-Guanajuato). 
Pienso enviarlos a la escuela hasta que tengan una carrera o un título (NL25Coahuila).

La educación es muy importante, porque yo no pude hacerlo, se lo voy a dar a mis hijos, que ellos estudien para que no sean como yo (M23-Oaxaca).

Por otro lado, las mujeres que dejan en sus comunidades de origen a familiares directos inician el proceso con la idea de finitud de ese proceso, es decir, desde el inicio del proceso mantienen que es algo eventual, por algunos años, no tienen el pensamiento de establecerse indefinidamente en Estados Unidos. La finalidad es permanecer algunos años para mantener a sus familias mandándoles dinero y conseguir ahorrar dinero suficiente para mejorar las condiciones de vida de sus familias. Y no sólo en lo que se refiere a los hijos/as, sino también a los padres/madres, la mujer mantiene el rol reproductivo al tener que volver para cuidarlos mientras que el hombre no manifiesta este rol en su proceso migratorio. Sirva como ejemplo el siguiente testimonio:

Pues mi hermano dice, como él es solo, ni tiene esposo ni familia, es sólo, él no traía pensamiento sobre cuando iba a regresar, sólo venía a trabajar. Pero yo sí por mi hijo. Yo más o menos lo mínimo cuatro años, porque voy pensando en mi madre, de que ya está grande, yo digo no pues que Dios me la va a proteger (NL22-Guatemala).

Por ello es frecuente que las mujeres vuelvan a cruzar la frontera para atender a hijos/as, padres o madres enfermas.

Sí, porque como ya le dije, que ella trabaja en el campo. Antes no trabajaba, yo le mandaba. Sus medicinas, también, su suero. Y ella a lo mejor te dice, no te vayas, aquí, si Dios dice que ya, pues ya. La pobreza también dice, no es bonita la pobreza. Me dijo bueno, pues si te quieres ir, pues vete, pero yo de mi parte, no quiero que te vayas. Me voy, para que usted esté bien (M33-Guerrero).

Pero ahorita ella se le vino una niña (tuvo una hija) y este, la operaron también de la vesícula y no quedo muy bien, no sé, o se equivocaron, no se que o no le pusieron bien una medicina. Y estuvo muy mal, hasta ahorita no se bien, porque no he hablado con ella. (...) Estaba en un hospital, pero Luis la sacó de un pozo porque dice que le estaban poniendo muchos medicamentos y ya sentía que no le hacían bien. Mejor la sacó y le busco un doctor particular y está en su casa.......pues que nada más tenga paciencia, (comienza a llorar) si es como ahorita que yo quiera pasar por mi hija (M45-Veracruz).

Yo me quise regresar porque aquí están mi mamá y mi papá (M30-Veracruz).

Otro de los cambios fundamentales de la migración de la mujer alcanza a los hombres y su implicación en las tareas reproductivas. Así, algunos 
estudios sugieren que cuando la migración es femenina, algunos hombres que permanecen en las comunidades de origen pueden verse obligados - si no existen redes femeninas de apoyo- a hacerse cargo de las tareas reproductivas que hasta ese momento no asumían, alterándose las relaciones de género desiguales predominantes antes de la migración de la mujer (Curran, 2003).

Las mujeres migrantes, los peligros a los que se enfrentan y los recursos utilizados

Las desigualdades en la socialización de género afectan de forma importante en los motivos y en el transito o proceso migratorio haciéndose patente la vulnerabilidad de la mujer. En muchas ocasiones las mujeres huyen de situaciones de maltrato, desigualdad y abusos familiares de la comunidad de origen. Han sido abusadas por sus progenitores o padrastros o carecen de recursos porque no son tenidas en cuenta en el reparto de las herencias familiares, raptadas y convertidas en sirvientas de la familia del raptor.

Entrevistadora: ¿Cuándo tenía 16 años por qué dijo — me voy a Estados Unidos-?

Entrevistada: Pues fue un arranque porque mi marido, el papá de mis hijos, me golpeaba mucho pues ya no podía aguantar (...) me pegaba con el machete por todo el cuerpo (NL31-Honduras).

Estas mujeres buscan una vida mejor para ellas y para sus hijos e hijas y como consecuencia de la migración, ganan mayor autonomía, autoestima, poder de decisión, libertad y un mayor equilibrio en las relaciones de género. En este sentido, si bien la motivación económica tiene cierto carácter forzoso porque es una decisión que toman las mujeres después de valorar los riesgos y los beneficios al no encontrar oportunidades para tener una vida mejor en su propio país, existe otro tipo de migración asociada al tráfico ilegal y a la trata de personas que afecta especialmente a las mujeres y niñas.

Llegados a este punto es importante hacer la distinción entre tráfico ilegal de personas y trata de personas (Tabla 2).

A su vez, la trata de persona conlleva múltiples violaciones de los derechos humanos (Instituto Internacional de los Derechos Humanos, 2003): Retención de documentos de identificación, viajes, o de salud, imposición de deudas por transportes, alojamiento, alimentación, y otras necesidades básicas, amenazas de informar su condición migratoria a las autoridades 
golpes y abusos físicos, guardias que las vigilan o ejercen otros métodos de restricción de la libertad.

Tabla 2: Diferencias entre la trata ilegal y la trata de personas

\begin{tabular}{|l|l|}
\hline \multicolumn{1}{|c|}{ Trata Ilegal (coyote) } & \multicolumn{1}{c|}{ Trata de personas } \\
\hline Existe un cruce irregular de fronteras. & $\begin{array}{l}\text { Los desplazamientos pueden ser } \\
\text { legales o ilegales. }\end{array}$ \\
\hline $\begin{array}{l}\text { El desplazamiento no necesariamente } \\
\text { tiene como finalidad explotar a la } \\
\text { persona. }\end{array}$ & $\begin{array}{l}\text { El desplazamiento se da con fines de } \\
\text { explotación: sexual, laboral venta de } \\
\text { órganos... }\end{array}$ \\
\hline $\begin{array}{l}\text { Se usan documentos falsos o } \\
\text { procedimientos ilegales. }\end{array}$ & $\begin{array}{l}\text { No necesariamente hay documentos } \\
\text { falsos. }\end{array}$ \\
\hline $\begin{array}{l}\text { Existe consentimiento del que es } \\
\text { llevado aunque a veces hay falsas } \\
\text { promesas. }\end{array}$ & $\begin{array}{l}\text { No hay consentimiento, sino más } \\
\text { bien engaño y coacción. }\end{array}$ \\
\hline Siempre hay cruce de fronteras. & $\begin{array}{l}\text { La trata también puede ser interna, de } \\
\text { una región a otra dentro del mismo } \\
\text { país. }\end{array}$ \\
\hline $\begin{array}{l}\text { Es un delito contra el Estado, tanto de } \\
\text { origen como de destino. }\end{array}$ & $\begin{array}{l}\text { Es un delito contra las personas, se } \\
\text { violentan sus derechos. }\end{array}$ \\
\hline $\begin{array}{l}\text { No se coarta la libertad, generalmente } \\
\text { el trato termina al cruzar la frontera. }\end{array}$ & $\begin{array}{l}\text { Existe restricción de movimiento, la } \\
\text { persona permanece encerrada y } \\
\text { vigilada. }\end{array}$ \\
\hline
\end{tabular}

Fuente: Cabrera y Carrera (2005).

En este sentido, se recogen numerosos casos y denuncias de mujeres desaparecidas denunciadas por sus familiares.

Entrevistado: Hay mucho que hacer. Sobre todo dar a conocer cuáles son los derechos que todo ser humano tiene, son derechos universales (...) aquí en México abolimos la esclavitud (...) pero hay otro tipo de esclavitud disfrazado. Tantas mujeres engañadas que les ofrecen un trabajo en otros países y resulta que van a prostituirse $¿$ no? Entonces las obligan a prostituirse (...) se queda usted sorprendido de ver cómo sigue este problema de trata de personas.

Entrevistadora: ¿Mencionó usted que han recibido denuncias de mujeres desaparecidas?

Entrevistado: Sí, aquí los familiares vienen con frecuencia... (Representante del Gobierno del Estado de Veracruz).

En relación a las amenazas que reciben las mujeres migrantes debemos indicar que muchas de ellas son coaccionadas a través de amenazas a sus familiares, en mayor medida las amenazas se ciñen sobre sus hijos/as. 
Entrevistada: a ellas las amenazan con, con decirle, 'tus hijos te los voy a quitar, te los voy a quitar' sobre todo esto, 'si tú esto, yo te lo voy a quitar y tú te vas a ir y yo me quedo con ellos (Delegada Regional de la Comisión de Derechos Humanos de Tamaulipas).

La vulnerabilidad de las mujeres migrantes viene determinada no sólo por el peligro ante agentes policiales o ante la trata de blancas - "Dos policías me amenazaron con pistolas y abusaron de mí y hicieron lo que quisieron" (mujer de 31 años de Honduras) — sino también suelen ser amenazadas por su propio entorno familiar. En este sentido, encontramos testimonios que manifiestan chantajes y amenazas por parte de sus parejas para evitar que la mujer sea libre en la toma de decisiones y abandone la situación de opresión que sufre. "Si te vas te echo a los judiciales. (...) Me tenía encerrada (...) Él era ciudadano (de Estados Unidos), la mamá también y todos los familiares, entonces la mamá me decía que te voy a echar la migración..." (NL25-Honduras). Constatamos como el propio proceso de socialización vivido en su cultura de procedencia convierte a la mujeres en seres más vulnerables en cuanto no confían en sí mismas, en sus capacidades y reacciones pero por otro lado este mismo proceso les ha llevado a desarrollar unas estrategias de supervivencia como son los lazos y redes sociales a las que ya hemos aludido y son capaces de resurgir con fortaleza de situaciones adversas sobre todo cuando está en juego la supervivencia y porvenir de sus hijos e hijas.

Cuando llegan al lugar de destino la vulnerabilidad no desaparece y las mujeres emigrantes en muchas ocasiones sufren la explotación de personas del mismo sexo, mujeres, incluso de la misma cultura que han emigrado previamente y que ya están establecidas, que reproducen el modelo de explotación que ellas mismas han sufrido.

Una mujer mexicana relata así su primera experiencia de trabajo en Estados Unidos:

Sí. No, no se quería ir. Y a él no le gustaba ir porque, yo trabajaba allí en la cebolla, como yo ganaba, dependiendo de los costales que hiciera, hacía cuentas, dos o hacía los cien, entonces sacaba de quinientos a cuatrocientos. De ahí no más me quedaba yo con cien, porque la señora me quitaba lo demás, porque tenía que pagar renta y todo (M45-Veracruz).

La información recogida en el estudio de campo realizado en el Estado de Tamaulipas muestra cómo la mujer que inicia su proyecto migratorio a través de coyotes, presenta una gran vulnerabilidad y posee un alto riesgo de ser víctima de trata de personas. Por otro lado, muchas mujeres que son 
violentadas por los polleros, coyotes o incluso por compañeros de viaje, o aquellas que se encuentran indocumentadas y sin recursos para continuar su ruta a Estados Unidos, es posible que se vean involucradas en la prostitución y pornografía como una forma de pago de deudas.

(...) la mujer migrante centroamericana ya viene preparada, la mexicana no, o sea, la centroamericana ya vienen preparadas con las pastillas anticonceptivas desde que salen de sus países de origen y lo que viven en todo el transcurso de su camino, por varias cosas, entre ellas las violaciones que sufren en el camino que no es una ni dos veces, son varias veces (Sacerdote de la Casa del Migrante de Reynosa y Matamoros).

(...) muchas de ellas han tenido contacto con otras personas, la mayoría porque han hecho el viaje y son conocedoras en parte de los riesgos a los que se deben enfrentar, incluso algunas de ellas vienen preparadas, entre comillas, lo digo, para, bueno, esa posibilidad de sufrir una violación sexual, porque algunas de ellas toman anticonceptivos (Subdirectora de Estudios de la Quinta Visitaduría General de la Comisión Nacional de Derechos Humanos, México).

Las muchachas son violentadas, delante de todos, eh, eh, eh, no, no, no, terrible, o sea, hay historias... (Sacerdote de la Casa del Migrante de Reynosa y Matamoros).

El riesgo que tuvimos fue cuando nos dejó solos el poyero allí en la vía, nos abandonó (NL25-Coahuila).

Durante el proceso de migración las mujeres son expuestas a peligros, abusos incluso de sus propios compañeros de viaje, las personas que facilitan el transporte etc., en la medida en que se las sigue considerando incapaces e inferiores y al servicio de los hombres tanto a nivel sexual como en el trabajo doméstico y de cuidado.

Una mujer mexicana deportada en la Casa del Emigrante de Matamoros narra algunos de estos peligros:

No, he escuchado como la mujer, las que pasan, que son ilegales, pobrecitas, lo que pasa a la mujer. Unas han sido raptadas, las raptan, los que las llevan, pasan cosas que no, o no pagan, los matan o pasan algo. He oído yo mucho de eso. Y a los hombres también, pero corren más peligro las mujeres (M50-NL).

En la misma línea, la investigación muestra testimonios de cómo la voluntad de las mujeres migrantes no es tomada en consideración.

Entrevistado: Yo creo que las mujeres en general que desde que inician su viaje son mucho mas vulnerable que el hombre. Por el hecho de ser mujer quien la va a cruzar, trata de abusar de ella. 
Entrevistadora: se considera mas débil físicamente, por lo tanto, más vulnerable de entrada.

Entrevistado: Así es. Aquí no nos ha tocado una persona del sexo femenino que diga sabes que a mi en el momento de cruzar a mi me violaron o me paso algo así, ¿no? Pero, cuando estuve en Laredo me toco de saber de una mujer que la cruzaron, la violaron, la golpearon, pero pensaron que la habían matado y la dejaron allí, pero la mujer no estaba muerta. Sí, la violaron la golpearon, pero la golpearon mucho y pensaron que estaba muerta y la dejaron allí y a esta mujer la regresaron hasta México. Es el caso más feo, pero esto no es de aquí. Entrevistadora: Da igual el lugar, porque eso puede ocurrir en cualquier sitio. Entrevistado: exactamente, si.

Entrevistadora: normalmente a las mujeres les cuesta hablar ¿no? ¿O qué?

Entrevistado: Sí.

Entrevistadora: De lo que han pasado, de lo que han sufrido, quiero decir que no es fácil que cuenten las situaciones que han pasado (Miembro del grupo BETA de Matamoros, México).

Sin embargo, también hemos constado que en ocasiones la utilización del "pollero" da seguridad a la mujer proporcionándole alojamiento, compañía y estrategias para sobrevivir en el trayecto, aunque estos testimonios manifiestan este hecho como "cuestión de suerte".

Por suerte me tocó un buen pollero. Gracias a Dios, porque apenas éramos tres mujeres e iban cuatro polleros con nosotros. Ellos nos iban ayudando. Ellos decían, las mujeres adelante, pasen las tres mujeres adelante. Decían que aquí no se va a hacer nada malo a nadie o nadie intente hacer nada malo a una mujer. Nos trataban bien a nosotros, bueno, a todo el grupo porque no nos hicieron nada malo. Son buenos polleros porque no nos hacen nada malo (M23-Oaxaca).

Como hemos comprobado en la investigación realizada, la vulnerabilidad de la mujer que inicia el proceso migratorio hacia Estados Unidos, comienza desde el momento que decide emigrar porque en la mayoría de las ocasiones lo hace sin una planificación que le lleva a calcular los riesgos y costes del mismo, confiando en una protección que le proporciona sus creencias religiosas.

En la preparación del viaje sólo me encomendé a Dios y a la virgencita (NL42Veracruz).

Ellas vienen muy marcadas por una religiosidad fuerte en su corazón, sobre todo pidiéndole siempre a Dios que las acompañe. Es algo que el migrante y la migrante no pierden. O sea, pueden perder todo, pero la fe en Dios no la 
pierde porque viene con esa esperanza (Sacerdote de la Casa del Migrante de Matamoros y Reynosa, México).

Sus fuertes convicciones religiosas constituyen para ellas una fuerte protección frente a las adversidades y descuidan en muchas ocasiones los factores de seguridad del proceso tales como tener planificados todos los movimientos. Aunque en ocasiones las mujeres migrantes, sobre todo en el caso de centroamericanas que cruzan México, busca estos factores de seguridad en la compañía de un hombre mexicano al que se une durante el proceso migratorio, al ser conscientes de su mayor vulnerabilidad, pero esta estrategia no siempre las protege si no que muchas veces, constituye un problema para ellas.

Entrevistada: Lo que sí he tenido son mujeres migrantes que cruzan, son deportadas o llegan de alguna forma (...) porque hay una unión, no matrimonio, una unión libre con algún hombre mexicano y llegan aquí conmigo con sus hijitos o embarazada (...) el hombre la embarazó, tienen sus bebé pero luego las dejan, o ejercen violencia física o psicológica sobre ellas, con la amenaza de que, yo te puedo denunciar y te vas de aquí y yo me quedo con los niños (Delegada Regional de la Comisión de Derechos Humanos de Tamaulipas, México). En una ocasión un señor me fue a dar un ray (autoestop) pero luego se quiso pasar de lanza, ya sabe usted, y le dije que no, y me baje del carro en la primera gasolinera, me hice así como la que iba a ir al baño y ya no volví para atrás (...), estuve un rato escondida en la gasolinera, en los baños (...) estuve bastante rato hasta que dije ojalá que ya no vuelva. Tenía miedo, vaya a pensar que lo iba a denunciar y me fuera a matar (NL42-Veracruz).

Una cuestión que nos ha llamado la atención en la realización de las entrevistas es la escasez de mujeres migrantes acogidas en los centros o casa del migrante, conocedoras de que el número de mujeres que migran a Estados Unidos actualmente es tan elevado como el de hombres. Este hecho nos ha llevado a pensar que las mujeres pueden utilizar como recurso para protegerse en el proceso, redes informales de apoyo a lo largo del camino tales como familiares, amigos/as, familiares de vecinos/as que los acogen en sus casas y por tanto les separan de los peligros que suponen las estaciones de autobuses etc. Factor de protección que poseerían las mujeres mexicanas y no tanto las extranjeras (hondureñas, salvadoreñas etc.) que pasan a ser más vulnerables que las mexicanas. Esta capacidad la han desarrollado como consecuencia de haber sido socializadas dando importancia a la empatía, los lazos afectivos, la familia, redes de amigos/as, que les proporcionarán apoyo afectivo y también económico. En muchas oca- 
siones son las vecinas, amigas o familiares quienes les facilitan recursos para iniciar el proceso.

(...) accedemos a las mujeres migrantes que están en los albergues o en las estaciones migratorias, pero no podemos acceder a otras muchas que tienen unas redes sociales que les ayudan a..., en el proceso migratorio, es decir, tenemos algunos datos de un matrimonio que era el marido era el cuñado de no sé quien, que estuvo un tiempo allí en esta casa, entonces eso nos ha llevado a pensar que quizás se van a casa de la prima, de la vecina, es decir, crean una red para defenderse, precisamente, eh... se crean esas redes, y que después desde el lugar de... desde que inician el proceso migratorio, pues van parando en esos sitios... (Subdirectora de la Quinta Visitaduría General de la Convención Nacional de Derechos Humanos).

Ella fue (vecina) la que me dio una dirección allá, me ofrecen ayuda para irme (NL42-Veracruz).

Mis hermanos me mandaron dinero para mi pasaje y para el coyote. Cuando llegué a Reynosa donde cruzamos (...) Todo ese tiempo nos llevaron a una casa donde estuvimos tres días, me daban de comer. Donde nos tenían nos daban de comer. Yo siempre me quedé en la casa (M23-Oaxaca).

Las mujeres migrantes centroamericanas suelen realizar el trayecto a través de redes proporcionadas por familiares que se encuentran en el país de destino. Si bien nos encontramos que en ocasiones el apoyo final puede desaparecer cuando la mujer ha iniciado el viaje.

Entrevistado: Todo es una red (...) los enganchan en sus lugares de origen (...) cuando ya el familiar de Estados Unidos vio, que es cierto que viene la esposa o que viene la hermana o que viene un familiar, ya, dicen, oye, pues ya estoy en la frontera, este... ya me vas a ayudar, resulta que en Estados Unidos le dijeron que no te voy a ayudar. (...) Entonces lo que comienza las mujeres es a prostituirse para, porque no tienen dinero, entonces comienza la prostitución" (Sacerdote de la Casa del Migrante de Matamoros y Reynosa, México).

Nos llevan (refiriéndose a los polleros) a casas, nos encierran y nos ponen reglas (M23-Oaxaca).

Con todo lo expuesto podemos afirmar que hay mujeres que durante la migración afianzan las desigualdades de género y sufren sobrecarga de trabajo, desintegración de las familias en origen, aislamiento o violencia física y sexual; y la mayor parte de ellas sufren pérdidas en algunos aspectos, pero la representación de nuevos roles les ofrece ganancias y desarrollo de sus propios recursos para superar los retos que se les presentan. 


\section{Conclusiones}

A continuación exponemos las principales conclusiones del estudio dando respuesta a los objetivos planteados al inicio del artículo.

Respecto al primer objetivo, nos gustaría resaltar como la concepción de hombre y mujer viene determinada culturalmente, lo que proporciona al hombre y a la mujer una serie de actitudes y características que diferencia lo que se espera de lo femenino y de lo masculino. Por los resultados obtenidos en la investigación constatamos cómo en el contexto mexicano y centroamericano (mujeres migrantes extranjeras fundamentalmente de Honduras, Guatemala y El Salvador) la sociedad otorga una mayor importancia al hombre que a la mujer; por ejemplo, en varias declaraciones observamos cómo se da más importancia a la educación de los niños que a la de las niñas, reservando para las niñas el espacio más doméstico y familiar. Es decir, el rol reproductivo para la mujer y el rol productivo para el hombre.

Adentrándonos en las principales conclusiones asociadas al segundo objetivo, debemos indicar que tradicionalmente se consideraba que la mujer que iniciaba el proceso migratorio lo hacía con un papel pasivo dependiente del hombre, la mayor parte de las mujeres migraban acompañando a sus maridos o para reunirse con él (reunificación familiar). Esta visión mantiene el rol reproductivo de la mujer situándola por debajo del papel productivo que tiene el hombre y en situación de desventaja social: menos educación, menos oportunidades laborales, menos ingresos económicos, menos participación pública, menos iniciativa; y por tanto mayor vulnerabilidad. Su dependencia le desvaloriza frente a sí misma y la sociedad pudiendo ser abusada y golpeada, sin que esto se considere una violación de sus derechos.

Sin embargo, se va poniendo de manifiesto a través de diversas investigaciones, incluida los resultados que hemos mostrado, cómo la mujer adopta un rol activo en su proceso migratorio, tanto en la toma de decisiones e iniciativas, como en la consecución del objetivo de dicho proceso. Esta transformación también la hemos constatado en el importante papel productivo que desempeñan las mujeres migrantes, debido a su incorporación al mercado laboral, las mujeres constituyen un sostén económico familiar a través del envío de remesas, y se convierte en motor de desarrollo tanto del país en donde trabaja como del país al que envía sus ingresos.

En este sentido, debemos tener en cuenta que las mujeres migrantes no son sólo las mujeres que están en tránsito, sino que también son aquellas 
documentadas e indocumentadas que sí lograron cruzar y están en Estados Unidos, las que no consiguieron cruzar y están en alguna institución, que sí están en tránsito, y aquellas que perdieron la vida en su intento.

Otra de las características de las mujeres migrantes que las diferencian de los hombres es que no abandonan su rol reproductivo, aunque asuma el productivo. Las mujeres migrantes mantienen vinculaciones estrechas con su familia, sobre todo aquellas que tienen hijos menores. En numerosas declaraciones están presente sus hijos/as, todas las mujeres migrantes entrevistadas con hijos/as manifiestan su voluntad de migrar con sus hijos/ as para proporcionarles una vida mejor, estableciendo sobre todo como elementos importantes la educación, bienestar económico, seguridad y un futuro laboral. A su vez, nos encontramos este rol reproductivo en mujeres migrantes que una vez asentadas en Estados Unidos vuelven a cruzar la frontera enfrentándose a los peligros para atender a hijos/as, o padres/ madres enfermos/as. Por el contrario, el hombre migrante aunque en varios casos mande remesas a sus familiares, no mantiene esa vinculación afectiva, de hecho se ha constatado en diversas investigaciones que en algunos casos, los hombres migrantes constituyen un nuevo núcleo familiar en Estados Unidos.

En relación a la familia, también hemos observado cómo en muchos casos la familia se convierte en un elemento de coacción hacia la mujer. También, cuando las mujeres migrantes caen en redes de trata de personas, hemos constatado cómo estas redes suelen utilizar a los/as hijos/as u otros familiares para amenazar a las mujeres e involucrarlas en prostitución y pornografía.

En este sentido, y centrándonos en el tercer objetivo, hemos podido comprobar cómo las mujeres migrantes se enfrentan a una serie de riesgos, peligros y abusos incluso por parte de compañeros de viaje, lo que manifiesta su situación de desigualdad, porque muchos de estos abusos los sufren por el hecho de ser mujer. Se ha comprobado en las declaraciones que muchas de ellas asumen este riesgo y toman medidas contra el embarazo no deseado (sobre todo migrantes centroamericanas), pero no son conscientes de su verdadera situación de vulnerabilidad ya que en sus declaraciones consideran que esta situación es normal por ser mujer, sin tomar precauciones en cuanto a otros riesgos.

En este sentido, hemos podido constatar cómo las mujeres de nuestra investigación no suelen ser totalmente conscientes de los riesgos a los que se exponen en su proceso migratorio, actúan como se les ha enseñado teniendo en cuenta su condición de mujer: la planificación del viaje suele 
ser escasa, a veces incluso es improvisada y tienen como referencia las redes que han utilizado otras migrantes conocidas o la que le indica algún familiar que ha conseguido cruzar. A la hora de planificar el viaje no tienen en cuenta a qué instituciones pueden acudir, si se sienten vulneradas en sus derechos, a quién llamar, qué situaciones son de riesgo y cuándo se vulneran sus derechos, etc. La única protección que señalan de forma unánime en todas las declaraciones que realizan las mujeres migrantes es la de la fe, la protección de Dios, esta característica está presente en todas las entrevistas.

En consecuencia, constatamos como las mujeres migrantes a pesar de su vulnerabilidad nacida de las creencias de género de su cultura y de aquella por la que transitan, poseen una fortaleza y esperanza en un mundo mejor para ellas y sus hijos e hijas que les impulsan a afrontar todos los peligros del viaje.

\section{REFERENCIAS BIBLIOGRÁFICAS}

Agustín, Laura M., 2003,“Olvidar la victimización: los migrantes como protagonistas", en Development, núm. 46(3).

Cabrera, Dina Priscila y Carrera, Carlos Alberto, 2005, Trata de niñas, niños y adolescentes, con fines de explotación sexual comercial. Guatemala, AVANCSO.

Canales, Alejandro y Zlolniski, Cristian, 2001, "Comunidades transnacionales y migración en la era de la globalización" en Bravo, Jorge, Sánchez, Rolando y Schkolnik, Susana (ed.), Simposio Sobre Migración Internacional en las Américas, Notas de Población. San José, Costa Rica: Cepal, consultado el 10/10/2017, recuperado de http://www.eclac.org/publicaciones/xml/2/8852/lcg2124P_7.pdf

Carretero Palacios, Amparo, 2015, Migraciones y género. La feminización de la migración transnacional. Junta de Andalucía.

Ciurlo, Alessandra, 2015, "La migración femenina y los cambios en las relaciones de género en las familias: el caso de las transmigrantes colombianas en Italia" en Oasis, núm. 21, enero-junio.

Curran, Sara, 2003, Gendered migrant social capital, en Working paper del Center for migration and development. Princeton University.

D’Aubeterre Buznego, María Eugenia, 2005, "Mujeres trabajando por el pueblo: género y ciudadanía en una comunidad de transmigrantes oriundos del estado de Puebla”, en Estudios sociológicos, vol. 23, núm. 67.

García-Moreno, Cristina, 2015, "Trayectorias laborales de las mujeres migrantes cubanas en España”, en Revista Migraciones Internacionales, vol. 8, núm. 1, enero-junio. 
Godoy, Lorena, 2007, “Fenómenos migratorios y género: identidades femeninas remodeladas", en Psykhe, Santiago, vol. 16, núm 1.

Instituto Internacional de Derechos Humanos de Paul University, 2003, Esclavitud moderna: tráfico sexual en las Américas. América Central y el Caribe. IIDH, Estados Unidos.

Jolly, Susie, 2005, Género y Migración. Informe General. Bridge: Institute of Development Studies, UK.

Klein, Alejandro y Vázquez-Flores, Erika, 2013, “Los roles de género de algunas mujeres indígenas mexicanas desde los procesos migratorios y generacionales", en Journal of Behavior, Health and Social Issues, México, vol. 5, núm. 1.

León, Camila, 2014, “La retradicionalización de los roles de género en la maternidad transnacional: el caso de mujeres peruanas en Santiago de Chile", en Si Somos Americanos. Revista de Estudios Transfronterizos, vol. 14, núm. 1.

Levitt, Peggy, 1996, Social remittances: a conceptual tool for understanding migration and development, en Harvard Center for Population and Development Studies, Working Paper Series.

Martín, Emma, Martínez, Manuel Francisco y Martínez, Julia, 2014, Introducción a la Interculturalidad y a las Migraciones. Universidad de Sevilla y Junta de Andalucía, consultado el 5/10/2017, recuperado de http://www.juntadeandalucia.es/ export/drupaljda/Introduccion_interculturalidadymigraciones_US.pdf

Martínez Pizarro, Jorge, 2003, El mapa migratorio de América Latina y el Caribe, las mujeres y el género. Fondo de Población de las Naciones Unidas.

Micolta León, Amparo, 2007, “Migración internacional y desarrollo. El aporte de las mujeres", en Trabajo Social, núm. 9.

Monreal-Gimeno, Mª Carmen y Martínez-Ferrer, Belén, 2010, “Esquemas de género y desigualdades sociales”, en Luís Amador y Ma Carmen Monreal (coods.), Intervención social y Género, Madrid: Narcea.

Monreal-Gimeno, M M $^{\mathrm{a}}$ Carmen, Povedano, Amapola y Rodríguez, Antonio, 2012, en "Mujeres Migrantes", en Musitu Ochoa, Gonzalo, Mujer y migración. Los nuevos desafios en América Latina. México: Trillas.

Monzón, Ana Silvia., 2006, Las viajeras invisibles: mujeres migrantes en la región centroamericana y en el sur de México. Consejería en Proyectos.

Organización Internacional para las Migraciones (IOM), 2008, World Migration Report 2008: Managing labour mobility in the evolving global economy. Ginebra: OIM.

Palma, Silvia Irene, 2004, "Crónicas de amor. El sentido del amor en la mujer que tiene al hombre de su vida en Estados Unidos", en Palma, Silvia Irene, Después de Nuestro Señor, Estados Unidos: perspectivas de análisis del comportamiento e implicaciones de la migración internacional en Guatemala. Guatemala, FLACSO. 
Ramírez, Carlota y Míguez, Julia, 2005, Cruzando fronteras: remesas, género y desarrollo, Instituto Internacional de Investigaciones y Capacitaciones de las Naciones Unidas para la Promoción de la Mujer (INSTRAW).

Terrón-Caro, Teresa y Monreal Gimeno, Ma Carmen, 2014, "Mujeres migrantes en tránsito en la Frontera Norte de México: motivaciones y expectativas socioeducativas ante el sueño americano", en Papeles de Población, vol. 20, núm. 82.

\section{RESUMEN CURRICULAR DE LAS AUTORAS}

\section{Rocio Cárdenas Rodríguez}

Doctora en Pedagogía por la Universidad de Sevilla. Profesora e Investigadora de la Universidad Pablo de Olavide (UPO), Sevilla (España). Directora General de Programación Cultural y Social, responsable de la Oficina de Igualdad de la UPO. Directora del proyecto emergente "Atención a la diversidad cultural desde una perspectiva de género". Líneas de investigación: diversidad cultural, género y educación. Miembro del Grupo de Investigación en Acción Socioeducativa de la Sociedad Iberoamericana de Pedagogía Social e investigadora del Proyecto Europeo Grupo de Género y Ciudadanía. Autora de numerosos artículos relacionados con la diversidad cultural y el género, investigadora en diferentes proyectos a nivel nacional e internacional.

Dirección electrónica: mrcarrod@upo.es

\section{Teresa Terrón Caro}

Es Doctora en Pedagogía por la Universidad de Sevilla (España). Profesora en el Departamento de Educación y Psicología Social de la Universidad Pablo de Olavide, Sevilla. Entre las publicaciones más recientes destacan: Vicente Llorent Bedmar y Teresa Terrón Caro, 2013, "La inmigración marroquí en España: Género y Educación", en Revista Estudios sobre Educación, vol. 24; Vicente Llorent Bedmar y Teresa Terrón Caro, 2013, "Políticas socioeducativas de integración de los inmigrantes en Alemania, España y Francia”, en Pedagogía Social. Revista Interuniversitaria, núm. 21; Rocío Cárdenas Rodríguez, Teresa Terrón Caro y José Luis García Llamas, 2012, "Actitudes ante la diversidad cultural de la juventud europea", en Carmen Monreal et al. (coord.), Juventud europea. Valores y actitudes ante las instituciones democráticas, Dykinson, Madrid y Teresa Terrón Caro, 2012, "La mujer en el Islam. Análisis desde una perspectiva socioeducativa", en El Futuro del Pasado, núm. 3.

Dirección electrónica: mttercar@upo.es 


\section{María Carmen Monreal Gimeno}

Licenciada en Pedagogía y Filosofía por al Universidad de Valencia, Psicología por la Universidad Complutense de Madrid y Doctora en Educación por la Universidad Nacional de Educación a Distancia (UNED). Profesora titular de Psicología Social de la Universidad Pablo de Olavide desde 2002. Directora del primer programa de formación del profesorado de la uPo. Codirectora del Máster Género e Igualdad de la Universidad Pablo de Olavide (2010 hasta actualidad). Investigadora principal de proyectos, I+D+I (2004-2007) Los Jóvenes europeos: valores constitucionales e instituciones democráticas y actualmente de GENDERCIT. Publicaciones: "La prevenzione della violenza di genere a traverso de l'educazione al superamento degli stereotipi", en Genere e globalizzazione (2010); "Esquemas de género y desigualdades sociales", en "Intervención social y género" (2010); "Mujeres migrantes" en Mujer y migración. Los nuevos desafios de América Latina (2012).

Dirección electrónica: mcmongim@upo.es 